\title{
Valoração econômica do complexo de cachoeiras de Presidente Figueiredo,
}

\author{
Amazonas, Brasil \\ Economic evaluation of the waterfall complex of Presidente Figueiredo, Amazonas, Brazil \\ Valor económico del complejo cachoeiras del Presidente Figueiredo, Amazonas, Brasil
}

Recebido: 29/06/2021 | Revisado: 04/07/2021 | Aceito: 09/07/2021 | Publicado: 21/07/2021

Camilo Yunes Neto

ORCID: https://orcid.org/0000-0003-0811-4515 Universidade Federal do Amazonas, Brasil Superintendência da Zona Franca de Manaus, Brasil E-mail: camiloyn@gmail.com

Alexandre Almir Ferreira Rivas

ORCID: https://orcid.org/0000-0003-1794-8909

Universidade Federal do Amazonas, Brasil E-mail:central.rivas@gmail.com

Valdiney Ferreira de Almeida

ORCID: https://orcid.org/0000-0002-6817-9284

Instituto Federal do Amazonas, Brasil

E-mail: valdiney.almeida@ifam.edu.br

Marcelo Limont

ORCID: https://orcid.org/0000-0002-3400-9738

Universidade Positivo, Brasil

E-mail: marcelo.limont@up.edu.br

\begin{abstract}
Resumo
Estudos de valoração econômica de recursos ambientais são proposições aproximadas em termos monetários para bens naturais que não possuem valor definido. Este trabalho tem como objetivo estimar o valor econômico do complexo de cachoeiras em Presidente Figueiredo, município do estado do Amazonas, Brasil. Utilizando de referenciais da economia ambiental, buscou-se identificar os efeitos da ausência de valor do conjunto de ativos que compõem esse patrimônio natural. A pesquisa tem caráter quantitativo e o método utilizado foi o de Valoração Contingente. Foram recolhidas 257 amostras, obtidos por meio de entrevistas e questionários. Com auxílio da variável beta estimou-se, em média, que os visitantes estariam dispostos a contribuir para as melhorias hipotéticas a serem implementadas no complexo de cachoeiras de Presidente Figueiredo (CCPF), tanto em termos de infraestrutura quanto de conservação da biodiversidade com aproximadamente $13 \%$ da sua renda diária. Isso revela um patrimônio ambiental, de aproximadamente $\mathrm{R} \$ 35.000 .000,00$, e um potencial rendimento de $\mathrm{R} \$ 4.000 .000,00$ anual.
\end{abstract}

Palavras-chave: Valoração; Contingente; Amazônia; Ecoturismo; Bem-estar.

\begin{abstract}
Studies of economic valuation of environmental resources are approximate propositions in monetary terms for natural assets that they do not have market value. This work aims to estimate the economic value of the waterfall complex in Presidente Figueiredo, municipality in the state of Amazonas, Brazil. Using environmental economics references, we sought to identify the effects of the lack of value of the set of assets that make up this natural heritage. The research is quantitative in nature and the method used was Contingent Valuation. 257 samples were collected, obtained through interviews and questionnaires. With the help of the beta variable, it was estimated, on average, that visitors would be willing to contribute to the hypothetical improvements to be implemented in the Presidente Figueiredo waterfall complex (CCPF), both in terms of infrastructure and biodiversity conservation with approximately $13 \%$ of your daily income. This reveals an environmental heritage of approximately $\mathrm{R} \$ 35,000,000.00$, and a potential income of $\mathrm{R} \$ 4,000,000.00$ annually.
\end{abstract}

Keywords: Valuation; Contingent; Amazon; Ecotourism; Welfare.

\section{Resumen}

Los estudios sobre la valoración económica de los recursos ambientales son proposiciones aproximadas en términos monetarios para activos naturales que no poseen. Este trabajo tiene como objetivo estimar el valor económico del complejo de cascadas en Presidente Figueiredo, municipio del estado de Amazonas, Brasil. A partir de referencias de la economía ambiental, se buscó identificar los efectos de la falta de valor del conjunto de bienes que componen este patrimonio natural. La investigación es de naturaleza cuantitativa y el método utilizado fue la Valoración Contingente. Se recolectaron 257 muestras, obtenidas a través de entrevistas y cuestionarios. Con ayuda de la variable beta, se 
estimó, en promedio, que los visitantes estarían dispuestos a contribuir a las hipotéticas mejoras a implementar en el complejo de la cascada Presidente Figueiredo (CCPF), tanto en términos de infraestructura como de conservación de la biodiversidad con aproximadamente $13 \%$ de sus ingresos diarios. Esto revela un patrimonio ambiental de aproximadamente $\mathrm{R} \$ 35.000 .000,00$ y un ingreso potencial de $\mathrm{R} \$ 4.000 .000,00$ anuales.

Palabras clave: Valoración; Contingente; Amazonas; Ecoturismo; Bienestar.

\section{Introdução}

Há prevalência na sociedade de consumo por bens manufaturados. O desprezo dos recursos naturais frente aos bens já industrializados se dá porque os serviços prestados por aqueles, em seu estado natural, não são mensurados e internalizados nas escolhas. Até mesmo quando, raramente, levados em consideração, é de maneira tendenciosa. Assim, quem opta por uma atividade econômica que causará a supressão de um fragmento de área verde, normalmente, não avalia o valor econômico vinculado ao capital natural que a área desmatada pode ter. Para Costanza, et al. (1997) os valores atribuídos não são adequadamente quantificados, lhes dando, por consequência, pouco valor.

Segundo Higuchi, et al. (2009) uma floresta, por exemplo, é composta por uma infinidade de partes, mesmo as menores têm respectivamente sua importância própria e coletiva uma com as outras. Entre as várias funções de uma floresta no funcionamento de ecossistemas, a principal delas é a proteção de todas as outras formas de vida, sendo inevitável a sua permanência para o ecossistema equilibrado.

Nem todos os indivíduos são capazes de dimensionar valor econômico de recursos naturais, ou mesmo ter a dimensão dos serviços prestados por esses. Quando mensurados, por vezes, têm como premissa o pensamento limitado de trocas comerciais de bens e serviços já transformados. O fato dessa visão distorcida, para com os recursos naturais em seu estado bruto, continuar a ser usada é porque simplesmente não existe valor econômico pré-definido para tais. Além disso, para Higuchi, et al. (2009), os efeitos totais de uma supressão vegetal não são percebidos no curto prazo, ou antes que os benefícios dessa troca, aparentemente vantajosa, se cessem.

Por isso, para Motta (1997), determinar o valor econômico de um recurso ambiental se torna importante para estimar, não somente seu próprio valor em unidades monetárias, mas também em relação aos outros bens e serviços já disponíveis naquela economia, cuja noção de valor já é bem estabelecida.

Convém enxergar a categoria da valoração econômica de ativos naturais como diálogo comum entre conservacionistas e preservacionistas quando se trata de utilização indireta destes recursos naturais, pois é intersecção pacífica entre a agenda econômica necessária para inserção de um local não antropizado no sistema capitalista e ao mesmo tempo a da manutenção das relações étnicas, culturais e sociais que encontram no bojo da preservação a razão da sua existência.

Mendonça e Alecrim (2006) observaram que as cachoeiras, balneários e corredeiras do município de Presidente Figueiredo, no Amazonas, correm sérios riscos de preservação, devido, em grande parte, ao fluxo de visitantes que todos os anos usufruem de maneira predatória do local. A contaminação de corpos d'agua, o descarte inadequado de resíduos sólidos e destruição de matas ciliares foram relatados no estudo como os principais problemas ambientais relacionados à atividade turística.

O fluxo turístico ocorre durante todo o ano e intensifica-se no período de junho a outubro quando predomina o sol do verão amazônico. No entanto, segundo Cavalcante e Lopes (2007) o maior fluxo turístico ocorre durante as festas promovidas pela prefeitura

O somatório do rápido aumento populacional estimado pelo IBGE (2018) -aproximadamente 30\% em oito anos pressões imobiliárias e comerciais, segundo a SEMA (2018) e a ausência de medidas de valor, traçam um cenário futuro de piora da qualidade ambiental para o município nos próximos anos, o que prejudicaria fortemente o setor do ecoturismo local. 
Questões como a exposta, para Rivas (2014), são estudadas pela economia ambiental. Dividindo-se em três o conjunto de ativos que compõe um patrimônio natural. O primeiro conjunto, dos recursos naturais, cujo uso necessita da utilização de capital fixo e trabalho. A segunda categoria é a dos recursos físicos de fluxo, que normalmente são renováveis e não exauríveis e, a terceira categoria, de ativos ambientais, são os recursos denominados ambientais. Acerca dessa última categoria, os recursos não possuem valor definido por mercado. Para mensurá-los utiliza-se formas de medir os benefícios que sua existência gera.

Fearnside (2009) alerta que as ferramentas de valoração econômica não podem sugerir a banalização de trocas de serviços ambientais equilibrados ecologicamente por contrapartidas monetárias ou medidas compensatórias sem a mesma relevância ecológica para uma determinada região. Segundo Kahn (2008) há de se ter cautela ao valorar um ativo natural porque pode-se subestimar o valor real do ativo, já que não existem ferramentas próprias para tal. Utiliza-se do arcabouço já disponível presente nas noções de valor dos mercados de bens e serviços transformados.

Por outro lado, a completa ausência de uma estimativa em termos monetários de componentes ambientais prejudica o diálogo necessário entre crescimento econômico e preservação. Assim, para Constanza, et al. (1997), a negligência nos esforços da criação e aperfeiçoamento de técnicas de valoração ambiental compromete a sustentabilidade dos recursos pois, se depreende sua errada infinitude.

Em recente compilação de trabalhos Paul Romer e Nordhaus, vencedores do prêmio Nobel de 2018, tiveram suas contribuições respeitadas por questionarem as mudanças globais em um contexto de crescimento econômico e avanço tecnológico. Dentre as contribuições, uma de relativo interesse e foco teórico desse trabalho é a questão das falhas de mercado e as suas externalidades.

Hardin (1968) abordou as externalidades introduzindo o conceito da tragédia dos comuns, explicando o que acontece com os bens que não são de particulares; os que a eles não se possa atribuir valor monetário ou que não seja possível atribuir limites de propriedade. Assim, sugere-se, ser possível identificar sinais da tragédia dos comuns no complexo de cachoeiras de Presidente Figueiredo.

A possibilidade de um cenário catastrófico, em um breve futuro, por diversas evidências concretas e teóricas, motivou a execução deste trabalho. Presidente Figueiredo: local onde é possível o desenvolvimento de atividade econômica pujante cuja raiz esteja fincada nos preceitos da sustentabilidade, por meio do ecoturismo, está dando sinais de que pode estar sob grave ameaça. O objetivo desse trabalho é, portanto, estimar valor econômico, monetário, para o complexo de cachoeiras do município de Presidente Figueiredo/AM.

\section{Revisão Teórica}

Quanto ao referencial teórico utilizou-se o da economia ambiental. Para compreender como a estimativa de valor monetário para um ativo ambiental pode contribuir para sua conservação é necessário auxílio da microeconomia, aqui representada pela economia ambiental. Sob essa roupagem, segundo Rivas (2014), as falhas de mercado, na Tabela 1, são as formas de diagnóstico das ineficiências na alocação de recursos e fatores de produção. 
Quadro 1 - As falhas de mercado.

\begin{tabular}{|l|l|l|}
\hline Falhas de Mercado & Característica & Exemplo \\
\hline Competição Imperfeita & $\begin{array}{l}\text { Estruturas de mercado pouco } \\
\text { competitivas que geram distorções } \\
\text { nospreços quantidades da economia }\end{array}$ & $\begin{array}{l}\text { Poucos produtores de determinado } \\
\text { bem obtendo lucros acima do natural }\end{array}$ \\
\hline Informação Imperfeita & $\begin{array}{l}\text { Falta de conhecimento dos } \\
\text { verdadeiros custos e benefícios de de } \\
\text { determinado bem }\end{array}$ & $\begin{array}{l}\text { O desconhecimento por parte da } \\
\text { população dos efeitos do aquecimento } \\
\text { global }\end{array}$ \\
\hline Bens Públicos & $\begin{array}{l}\text { Mercados que não são ofertados por } \\
\text { privados devido sua inerência de } \\
\text { coletividade }\end{array}$ & $\begin{array}{l}\text { Disponibilização de segurança pública } \\
\text { a qualquer cidadão }\end{array}$ \\
\hline Intervençães governamentais excessivas & $\begin{array}{l}\text { São políticas públicas que visam } \\
\text { atingir finalidade própria e ocasionam } \\
\text { mudanças na estrutura de custos } \\
\text { individuais e sociais }\end{array}$ & $\begin{array}{l}\text { A política de colonização da } \\
\text { Amazônia na década de 60 e 70. }\end{array}$ \\
\hline Externalidade & $\begin{array}{l}\text { É a socialização de custos } \\
\text { (externalidade negativa) ou de } \\
\text { benefícios (externalidade positiva) } \\
\text { privados. }\end{array}$ & $\begin{array}{l}\text { A poluição de corpos d'água; desastres } \\
\text { ambientais. }\end{array}$ \\
\hline
\end{tabular}

Fonte: Rivas (2014).

Para Varian, (1987) e Rivas (2014), a presença de falhas de mercado, evidencia que Custos Marginais Sociais - CMS - e Benefícios Marginais Sociais - BMS - não estão em equilíbrio pelas forças de mercado. Na Figura 2, observa-se a distância entre as curvas CMP e CMS, ambas cortadas pela curva BMP. O triângulo azul, supondo que os direitos de propriedades não são definidos e que não há aplicabilidade do Teorema de Coase, é a área destinada a representar a externalidade devido ao uso sem parcimônia dos bens naturais de Presidente Figueiredo.

Figura 1 - Intersecção das curvas de custos marginais privados e sociais na curva de benefício marginal social.

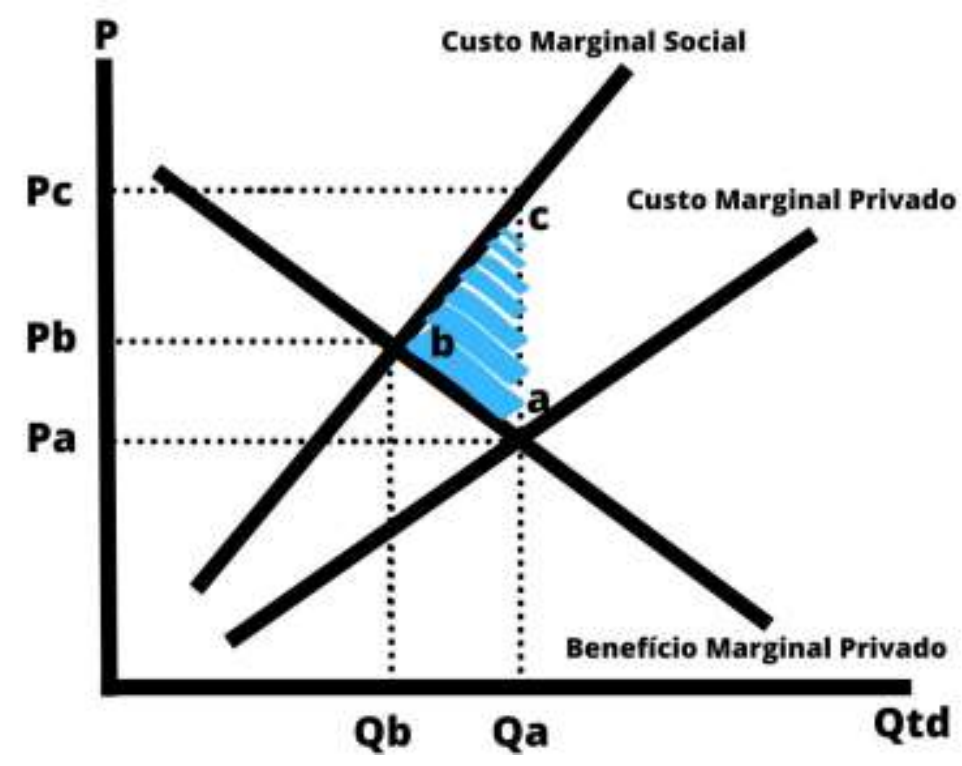

Fonte: Autores (2021)

Motta (1997), diz que deve haver um custo maior para o privado. Esse sobrepreço, deve ser exatamente o valor da externalidade negativa gerada. Para sua determinação é preciso identificar custos externos que, somados ao preço de mercado representa o preço social. Cabe dizer que esse sobrepreço é conhecido como imposto de Pigou. 
É possível ver em outras categorias a aplicação do tema. Em 2018, Levine e Macey publicaram no Yale Journal o caráter pigouviano da lei "Dodd-Frank". Os autores elucidam a relação das externalidades no mercado financeiro e como a norma internaliza esses custos, aproximando-os do custo social.

Devido a inerência da existência humana, é aceitável que haja um nível de degradação ambiental ou um estoque de dano já alcançado para um determinado local. Sob o bojo da economia ambiental, e a partir desse pressuposto as unidades marginais se tornam o objeto da análise, para Rivas (2014).

Em outros termos, é como se o nível de degradação ambiental já ocorrida em determinado local ao longo dos anos não modificou de maneira irreversível aquele ambiente, e esse é o limite que se tolera, devendo-se taxar possíveis novos danos que possam ocorrer nessa região. Assim, para atingir o ponto máximo tolerável de degradação ambiental marginal e custos marginais igualmente aceitáveis, estudos de valoração ambiental são utilizados.

Ademais, é preciso abordar a noção de valor. Para Nogueira et, al. (2000), o valor de um bem é determinado pelas pessoas que o consomem. A escolha de um bem qualquer revela a quantia, em unidades monetárias, que esse indivíduo está disposto a pagar para adquirir tal mercadoria e o quanto deixará de consumir de outras tantas.

Para bens sem valor predeterminado, como um fragmento de floresta em seu estado natural, o valor total pode ser decomposto em valor de uso e o valor de não utilizar esse recurso, segundo Rivas (2014). O valor de uso pode ser dividido ainda em seu valor de uso direto, seu valor de uso indireto e ainda um valor de opção.

Nogueira $e t$, al. (2000) trouxeram, Tabela 2, as seguintes noções de valor para bens naturais:

Quadro 2 - Decomposição da noção de valor para recursos naturais.

\begin{tabular}{|l|l|l|l|}
\hline \multirow{5}{*}{$\begin{array}{l}\text { Valor Total dos Recursos } \\
\text { Naturais (VTRN) }\end{array}$} & Valor de Uso (VU) & Valor de uso direto (VUD) & $\begin{array}{l}\text { Bens consumíveis ou } \\
\text { tangíveis. Ex: madeira } \\
\text { serrada ou acesso à } \\
\text { parques }\end{array}$ \\
\cline { 2 - 3 } & Valor de uso indireto (VUI) & $\begin{array}{l}\text { Funções ecossistêmicas } \\
\text { ou intangíveis. Ex: clima. }\end{array}$ \\
\cline { 2 - 3 } & $\begin{array}{l}\text { Valor de opção ou herança } \\
\text { (VO) }\end{array}$ & $\begin{array}{l}\text { Valor futuro pelo uso } \\
\text { direto e indireto de um } \\
\text { bem. Ex: conservação dos } \\
\text { recursos. }\end{array}$ \\
\cline { 2 - 3 } & Valor de não uso ou de existência (VNU) & $\begin{array}{l}\text { Valor da não utilização } \\
\text { futura dos recursos. Ex: } \\
\text { preservação dos recursos. }\end{array}$ \\
\hline
\end{tabular}

Fonte: Nogueira et al. (2000).

Para mensuração do valor de bens sem mercado, e por consequência sem valor predefinido, como o complexo de cachoeiras de Presidente Figueiredo, há diversas técnicas e métodos aplicáveis. Enquanto para Seroa da Motta (1997) pode-se usar seis métodos de valoração, outros autores se dividem predominantemente em abordagens de preferências reveladas e preferências declarada, como Freeman III, Herriges e Kling, (2014) e Rivas (2014). Não obstante, fica claro que os métodos ou técnicas são aplicados especificamente para cada caso e devem levar em consideração o objeto a ser estudado. Para valorar um ativo natural busca-se capturar a disposição a pagar (DAP) dos indivíduos, já que o valor é expresso pelo seu desejo de compra.

Bem como a noção de valor, o Método de Valoração Contingente (MVC) merece uma abordagem significativa. O método consiste em averiguar o valor que pessoas estão dispostas a pagar por uma suposta mudança em um determinado local. Pessoa e Ramos (1998) relembram que o Banco Mundial utilizou em alguns estudos essa técnica para estimar a disposição a 
pagar pela preservação da população de elefantes no Quênia e para valorar um parque nacional na Tailândia, além de ter sido usada pioneiro no caso "Exxon Valdez" em 1989.

Para o desenvolvimento do MVC é necessário aplicar questionários de situações hipotéticas a entrevistados, que ao declararem o valor que estariam dispostos a pagar por uma melhoria na qualidade ambiental de uma localidade, por exemplo, declaram sua DAP. É possível extrair de maneira análoga à disposição a receber (DAR) por uma perda, sendo essa, uma outra forma de mensurar valor para ativos ambientais.

Há discussão acerca do uso da DAP e da DAR. Para Pessoa e Ramos (1998), há grande discrepância nos valores obtidos entre as duas. Essa diferença tem nascimento em aspectos subjetivos: um deles é assimetria na avaliação de ganhos e perdas. Os indivíduos atribuem maior valor a perdas do que a ganhos. Pearce e Turner $(1990 ; 1993)$ encontraram discrepâncias de até três vezes da DAR para a DAP. Rivas (2014) trouxe passos detalhados para a aplicação dos questionários.

Desde os Pioneiros, Ciriacy-Wantrup, (1947), diversos estudos de MVC foram publicados. Na tabela 3 consta uma curta revisão, de forma cronológica de estudos aplicados às ciências ambientais e da sustentabilidade.

Bateman e Turner (1993) trouxeram à tona alguns possíveis vieses, e, portanto, cuidados a serem tomados, que se não observados podem prejudicar o processo de valoração ambiental utilizando o MVC, e se tratados permitem maior confiabilidade no modelo. São eles: o Viés do carona; o Viés Hipotético; o Viés da contabilidade mental; e, o Viés de informação. Há também a figura dos vieses de procedimentos que, quando tratados, diminuem erros. Para Bateman e Turner (1993) são: o Viés de agregação; o Viés do entrevistador. Outros vieses relacionados à instrumentação são expostos pelos autores. O Viés do veículo de pagamento e o Viés de ancoragem de lances.

Deduz-se que apesar da existência desses vieses, o método é referência para valoração de estudos como o aqui proposto e que com o passar dos anos diversas modelagens foram utilizadas para estimar de maneira mais confiável os parâmetros que irão compor os modelos econométricos. Para Leite (2006), a divisão em diferentes técnicas de elicitação de respostas permitem a aplicação de determinado modelo de regressão. Se por um lado perguntas do tipo aberto podem revelar valores de protesto ou valores nulos, perguntas do tipo fechadas ou do tipo referendo são mais fáceis de serem respondidas, pois aproxima-se ao mercado de bens e serviços comuns.

Quanto aos procedimentos estatísticos, Hanemman (1984) introduziu a função de probabilidade acumulada, ou logit, para perguntas do tipo referendo. Após a descrição desse modelo, segundo Leite (2006), os procedimentos passaram a ser cumprir três etapas de validação: avaliar a se há como diminuir os vieses do modelo; comparar os formatos das perguntas para obtenção de DAP e avaliar a forma de gerar os lances dos valores. O autor faz referência a outros modelos de obtenção de respostas: "bidding game"; "follow-up" e "ranking" e outros modelos de regressões econométricas como: Probit; Cloglog; Log; Loglog; Cauchit em alternativa ao modelo logit.

Haab e MacConnel (1998), sugeriram a utilização do modelo beta em equações do tipo MVC. Para tanto é necessária a utilização da variável dependente DAP máxima 1 e mínima 0.

Ferrari e Cribari-Neto (2004) propuseram usar beta com o MVC e descreveram pela primeira vez um modelo com erro considerando a média das respostas em termos de parâmetro e covariáveis.

Travassos (2012), utilizando a regressão beta, concluiu que a DAP média mensal por domicílio é de $\mathrm{R} \$ 13,22$ para manter conservada a área de um manguezal no estado de Pernambuco. Mais recentemente Whitehead (2016); Whitehead e Haab (2017) e Rhodes et, al. (2018) utilizam o MVC em análises de custo-benefício. 
Quadro 3 - Estudos de valoração ambiental utilizando técnicas de valoração contingente.

\begin{tabular}{|c|c|c|}
\hline Técnica utilizada & Autores e Ano & Resultados / Conclusão \\
\hline \multirow{11}{*}{$\begin{array}{l}\text { Avaliação } \\
\text { Contingente (MVC) }\end{array}$} & $\begin{array}{l}\text { Eutrirak \& Grandstaff, } \\
1986\end{array}$ & $\begin{array}{l}\text { O valor de uso estimado do Parque Urbano de Lumpinee, na } \\
\text { Tailândia, é de US\$650.000,00 }\end{array}$ \\
\hline & $\begin{array}{l}\text { Kramer, Sharma e } \\
\text { Munasinghe, } 1995\end{array}$ & $\begin{array}{l}\text { Os nativos de Madagascar estão dispostos a aceitar U\$S } 108 \text { por } \\
\text { ano para renunciar acesso à floresta no Parque Matandia, em } \\
\text { Madagascar. }\end{array}$ \\
\hline & $\begin{array}{l}\text { Ferrari e Cribari-Neto, } \\
2004\end{array}$ & $\begin{array}{l}\text { Proposição do modelo de regressão beta aperfeiçoando a elicitação } \\
\text { por referendo. }\end{array}$ \\
\hline & Souza e Mota, 2006 & $\begin{array}{l}\text { DAP média de R\$ } 7,72 \text { para o uso da área recreativa do Parque } \\
\text { Metropolitano de Pituaçu, na Bahia. }\end{array}$ \\
\hline & Bollino, 2009 & $\begin{array}{l}\text { Os consumidores italianos de energia estão dispostos a pagar os } \\
\text { subsídios do setor de energia elétrica renovável caso haja um } \\
\text { aumento de produção de } 19,130 \mathrm{GWh}\end{array}$ \\
\hline & Freitas et al, 2010 & $\begin{array}{l}\text { Moradores do PROSAMIM tem a DAP anual por família de R\$ } \\
164,00 \text { para uma melhoria na qualidade do Igarapés do Educandos, } \\
\text { em Manaus. }\end{array}$ \\
\hline & Travassos, 2012 & $\begin{array}{l}\text { DAP média mensal por domicílio é de } \mathrm{R} \$ 13,22 \text { para manter } \\
\text { conservada a área de um manguezal no estado de Pernambuco }\end{array}$ \\
\hline & Breves da Silva, 2014 & $\begin{array}{l}\text { DAP dos moradores de Manaus para com arborização urbana é de } \\
\mathrm{R} \$ 39,53\end{array}$ \\
\hline & Oliveira, 2016 & $\begin{array}{l}\text { Prejuízo anual ao bem-estar dos moradores do bairro da praia } \\
\text { vermelha, em Salvador é de } \mathrm{R} \$ 3.083 .174,51 \text {. }\end{array}$ \\
\hline & Whitehead, 2018 & $\begin{array}{l}\text { Benefício anual do programa de rastreabilidade das ostras do golfo } \\
\text { do México no valor de US\$ } 13.59 \text { milhões, com intervalo de } \\
\text { confiança de US } 6,5 \text { milhões. }\end{array}$ \\
\hline & Rhodes et. Al, 2018 & $\begin{array}{l}\text { Por meio da análise custo-benefício, os benefícios da introdução } \\
\text { de estoques de peixes "red drum" superam os custos. }\end{array}$ \\
\hline
\end{tabular}

Fonte: Autores (2020).

Quanto aos procedimentos estimativos, utiliza-se diretamente as medidas de DAP individuais para se inferir a coletiva. O MVC é obtido diretamente a partir de medidas hicksianas do excedente do consumidor. Por isso, uma curva pode ser estimada com as respostas de DAP. Normalmente, a curva de lances correlacionará os lances (DAP) em função das visitas $(\mathrm{Q})$, da renda $(\mathrm{Y})$, de fatores sociais como educação $(\mathrm{S})$ e outras variáveis explicativas $(\mathrm{X})$ além de um parâmetro da qualidade ambiental do lugar (E). Portanto têm-se que:

$$
D A P=f(Q, Y, S, X, E, n)
$$

\section{Metodologia}

Este artigo pode ser descrito como uma pesquisa descritiva, com abordagem quanti-qualitativa, pois, de acordo com Creswell (2010), o pesquisador baseia a investigação sob a hipótese de que a coleta de diversos tipos de dados - os aqui usados entrevistas e questionários - proporcionam uma melhor compreensão da problemática associada à pesquisa. Alinha-se, também, como um estudo de caso de um fenômeno contemporâneo, explicado por Yin (2015). Para Gil (2010) garantir a inserção do caso em seu contexto, visando conferir maior credibilidade aos resultados, exige-se a utilização de técnicas da 
pesquisa bibliográfica, documental, observação in loco e aplicação de questionário, as quais foram a fundação para a execução desta estrutura.

Presidente Figueiredo, espaço empírico do presente estudo, localiza-se nas coordenadas geográficas: $02^{\circ} 03^{\prime} 04^{\prime \prime} \mathrm{S} 60^{\circ}$ 01' 30"O, Figura 2. O acesso ao município se dá pela mesma estrada entre Manaus, capital do estado, e Boa Vista, capital de Roraima.

Figura 2 - Mapa de Presidente Figueiredo, Amazonas, Brasil.

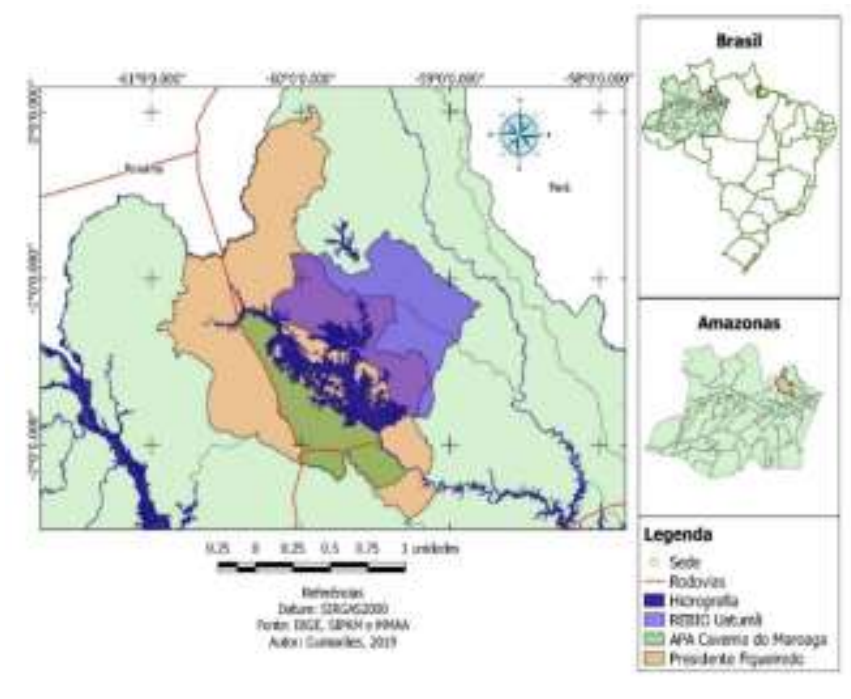

Fonte: Guimarães (2019).

Segundo o IBGE (2018) a área do município é de $25.422,235 \mathrm{Km}^{2}$ e a população é de pouco mais de 36000 habitantes, sendo o vigésimo município mais populoso do estado. A região faz parte da área denominada Região Metropolitana de Manaus. A economia do município é fortemente voltada para o ecoturismo. Isso inclui restaurantes, hotéis e empresas de atividades de aventura, além de outras mais atividades correlatas a turismo. O município tem aproximadamente 1,6\% do território do estado do Amazonas.

Oliveira, et al. (2011) relata que a história da ocupação do território de Presidente Figueiredo é dividida basicamente em duas fases diferentes, em relação às questões ambientais. A primeira, decorrente do período anterior ao surgimento oficial do município, em 1981, fortemente influenciada por ações de ocupação e desenvolvimento da região amazônica e a Emenda Constitucional 12/1981, na qual desmembrou o território de Itapiranga e Airão e criou legalmente o município.

A segunda fase, mais atual, está ligada a dois grandes projetos de desenvolvimento, nas décadas de 1970 e 1980: a hidrelétrica de Balbina e a exploração mineral de Pitinga que deram pujança ao município. Parte do município (como a figura mostra) apresenta uma política de ordenamento territorial que enaltece o capital natural em termos de sua proteção, considerando a existência da Reserva Biológica Uatumã, categoria de unidade de conservação de proteção integral e cujo uso direto dos recursos naturais é restrito, sendo priorizadas apenas ações de pesquisa, educação ambiental e proteção do patrimônio natural. Da mesma forma, a Área de Proteção Ambiental Caverna do Maroaga também surge como instrumento de ordenamento do território vinculado à conservação da biodiversidade, no caso como unidade de conservação da categoria de uso sustentável, cujo uso dos recursos naturais são orientados por ações de manejo orientadas ao atendimento dos objetivos de criação desta área protegida Neste caso as restrições de uso são indiretas, aspecto que permite a conciliação de atividades 
antrópicas no seu interior, como por exemplo a prática do turismo, desde que tenha um planejamento prévio. O fato destas unidades de conservação existirem sinaliza a importância ambiental do município, especialmente quando se considera a grande diversidade de espécies no bioma Amazônia.

Culturalmente o município é rico. Possui festas populares ao longo do ano: "carnachoeira", em fevereiro e a principal. A "festa do cupuaçu", em abril; o "festival folclórico", em agosto; o "festival de verão", em setembro; o "torneio de pesca do tucunaré, em outubro e o aniversário da cidade, no dia 10 de dezembro. Há, também, forte presença do povo "waimiri-atroari", cuja história está intimamente ligada à construção da BR-174, que deu acesso ao município.

Em relação ao seu potencial turístico, segundo o Ministério do turismo (2016), ostenta mais de cem cachoeiras catalogadas. Detém a segunda melhor nota, atrás da capital do estado, em potencial para atividades turísticas. Dos Reis e Telo (2010), destacam que o território do município tem grande parte sob a forma de Unidade de Conservação. A área de preservação ambiental do Maroaga alberga $14 \%$ da área do município de Presidente Figueiredo. Faz-se destaque para a reserva biológica do Uatumã, cuja área ocupa parte considerável do município.

É importante frisar que apesar do apelo turístico do município, faltam informações básicas acerca dessa atividade, o que mostra o desenvolvimento da atividade com pouco cuidado em relação ao seu planejamento. Tal cenário sugere que o Estado, em suas diferentes esferas de ação, não apresenta um plano de desenvolvimento da atividade a ponto de indicar sua implementação. Essa ausência em termos de política pública favorece o uso inadequado do patrimônio natural decorrente do turismo na região. Esta condição demonstra a importância do presente estudo, cuja contribuição pode contribuir para planejamento futuro da atividade e o consequente incremento no processo de implementação das políticas públicas associadas.

Os sites oficiais, por exemplo, não têm registro atualizado do número de visitantes de Presidente Figueiredo, apenas estimado. Segundo a empresa amazonense de turismo, AMAZONASTUR, o número aproximado de visitantes no ano de 2018 foi de 152.000 pessoas.

O plano de amostragem para valoração do complexo turístico de cachoeiras de Presidente Figueiredo, aderiu duas formas de coleta de dados. Entrevistas e questionários. Amostra mínima necessária: 252. Para um nível de confiança de 95\% e um erro amostral 0,06.

No primeiro método de obtenção de amostras, utilizou-se a técnica de entrevistas. Considerou-se uma amostra aleatória estratificada por sexo e faixa de idade. Os escolhidos para compor a base de dados foram abordados nas zonas sul, centro-sul, e aeroporto da cidade de Manaus. A cidade de Manaus foi escolhida para obtenção das entrevistas pois é de onde parte e retorna o maior fluxo turístico em direção ao município de Presidente Figueiredo. Foram obtidas 70 entrevistas, realizadas entre os meses de outubro, novembro e dezembro de 2019.

Houve duas pesquisas piloto que foram realizadas com o intuito de melhorar a qualidade do próprio questionário que foi aplicado nas entrevistas, como recomendado pela National Oceanic and Atmospheric Administration (NOAA), tendo sido necessárias pequenas alterações no corpo do texto no decorrer dessas pesquisas.

O critério para seleção do interlocutor a ser entrevistado foi o indivíduo ter ido ao município, com a intenção de realizar atividade de lazer nas cachoeiras, há no máximo três anos. O segundo critério foi não ser morador de Presidente Figueiredo. As perguntas se ativeram apenas ao campo da pesquisa, ou seja, deixou-se claro ao entrevistado que se tratava de situação hipotética e que os dados seriam utilizados apenas no escopo da pesquisa desenvolvida. Ademais, buscou-se conter as seguintes características: ser breve e conciso. Preocupou-se em não induzir o entrevistado a erros de entendimento do objeto, ou seja, evitou-se o viés da informação. Não foi necessário a identificação pessoal.

O segundo método de obtenção de amostras foi a técnica da aplicação de questionários em ferramentas online. Para essa etapa utilizou-se o suporte computacional do Google Formulários. O Formulário permaneceu disponível nos meses de outubro, novembro e dezembro de 2019 e no mês de janeiro de 2020. O conteúdo era basicamente o mesmo do aplicado por 
meio de entrevistas, com algumas pequenas alterações para evitar outros possíveis vieses aos voluntários que responderam. Nesse método foi obtido 194 respostas. Diferentemente das entrevistas, não havia critérios de inclusão e exclusão, sendo esse trabalho feito durante o tratamento dos dados, permanecendo 187 formulários. Nesse formato, a divulgação se deu em páginas da internet e com ferramentas de divulgação, chamadas de "gerenciadores de anúncio para impulsionamento", em redes sociais. Com essas ferramentas é possível escolher os locais onde sua pesquisa irá aparecer para quem estiver acessando as redes sociais no perímetro escolhido, que no caso foram os mesmos das entrevistas.

Tanto o questionário quanto o formulário tinham perguntas fechadas, do tipo sim e não, acerca dos dados do perfil socioeconômico, na primeira seção. Na segunda seção um breve texto introdutório contextualizou o tema. O texto teve como objetivo evitar possíveis respostas contendo emoções e informações notadamente não condizentes com a realidade socioeconômica do entrevistado, evitando vieses do tipo hipotético. Na terceira seção, vieses de contabilidade mental foram mitigados relembrando aos entrevistados alguns atrativos naturais do município. Na quarta seção, a DAP do complexo de cachoeiras foi questionada. Optou-se por usar perguntas abertas de forma que não induzisse os entrevistados ao viés de ancoragem. Quanto as escolhas das unidades monetárias em reais e a forma de pagamento. de uma possível taxa, sendo pela internet sem burocracias são para evitar vieses do tipo veículo de pagamento. Na quinta e última seção informações sobre número de viagens com fins turísticos e custos de viagem foram perguntados para enriquecer a análise e possibilitar a comparação futura com outros métodos de valoração.

Quanto ao modelo beta, segundo Travassos, et. al, (2018), a opção de usá-lo com o método da valoração contingente é devido a versatilidade da distribuição beta para modelar uma variedade de incertezas, de modo que se torne um modelo mais flexível e permita a melhor compreensão dos detalhes e erros dos dados da amostra.

Ferrari e Cribari-Neto (2004), os autores do modelo beta para valoração contingente, encorajam a utilização do método quando é possível enquadrar a variável resposta contínua em um intervalo unitário, ou seja, entre zero e um. Elucidam que o método atende os pressupostos do MVC e ajusta de maneira mais eficiente a disposição máxima a pagar. No caso, a variável dependente é a proporção da DAP em função da renda diária.

No modelo beta aplicado ao MVC, assume-se que a variável dependente segue a distribuição de probabilidade beta com parâmetros representados pela média e a precisão "phi”. Além disso, Ferrari e Cribari-neto, (2004) dizem que os parâmetros de regressão são interpretáveis em termos da média da variável de interesse, o modelo é naturalmente heteroscedástico e sua flexibilidade acomoda diversas formas de assimetrias.

Segundo Travassos, et. al, (2018), a abordagem econométrica para estimar a DAP usando o modelo beta, em vez do clássico modelo logístico tem a vantagem de estimar a proporção média da renda que o respondente aceita pagar diretamente pela hipótese proposta. Antes, as estimativas eram feitas a partir da estimativa da probabilidade de aceitar ou rejeitar o valor oferecido nas entrevistas, chamada de técnica de referendo. Para os autores, o modelo é um facilitador, pois é mais flexível que a abordagem clássica devido a capacidade de sua densidade observar vários formatos.

Assim, o modelo beta representa uma abordagem paramétrica viável com as vantagens da flexibilidade de sua distribuição. Para Travassos et. al (2018), o modelo possui uma interpretação econômica semelhante à abordagem do referendo de Hanemann (1984) e permite que a estimativa de DAP seja consistente com os critérios mínimos definidos por Haab e McConnell (1998), quanto às etapas de estimativa e cálculo da DAP.

Ferrari e Cribari-Neto (2004) desenharam o modelo de regressão beta assim: $\boldsymbol{g}\left(\boldsymbol{\mu}_{\boldsymbol{t}}\right)=\sum \boldsymbol{x}_{\boldsymbol{t i}} \boldsymbol{\beta}_{i}=\boldsymbol{\eta}_{\boldsymbol{t}}$. Onde $\beta=\left(\beta_{1}, \ldots \beta_{k}\right)^{T}$ é um vetor de parâmetros desconhecidos a serem estimados; $x_{\mathrm{t}}^{T}=\left(x_{\mathrm{t} 1}, \ldots, x_{\mathrm{th}}\right)$ são os valores de $\mathrm{k}$ variáveis explicativas que são fixas e desconhecidas, e g é função monótona e duplamente diferenciável que transforma valores do intervalo $(0,1)$ na função de ligação. 
De posse dos dados, o primeiro tratamento após a exclusão das amostras inconsistentes, foi a aproximação conservadora de respostas abertas de valores. A segunda foi a introdução de uma variável beta, cujo valor é obtido pelo quociente da disposição a pagar individual pelas melhorias propostas nos questionários, em função da renda mensal declarada, dividido por 30, número médio de dias no mês. O valor mínimo de beta considerado foi de 0,001 e máximo 0,999. Assim foi possível respeitar os parâmetros do modelo beta.

Pelo fato de o modelo trabalhar com variáveis cujos valores são contínuos, entre zero e um, foi necessário atribuir uma função probabilidade para cada variável explicativa. Para respostas de renda e a DAP, foram associadas faixas de valores, quatro para cada uma das variáveis. Para respostas categóricas foi associada uma probabilidade da resposta em função do universo das amostras. Além disso, um parâmetro probabilidade do pagamento da DAP declarada foi introduzida, sendo obtida pelo inverso da diferença declarada e a unidade. O objetivo é deixar as variáveis explicativas sob a mesma premissa de beta: contínuas, dentro do intervalo zero e um.

O modelo, por sua natureza, necessita do uso de funções de ligação para as estimativas. O objetivo dessas funções de ligação é linearizar a relação entre a resposta média e os preditores. Foram testadas diversas funções de ligação, sendo escolhida a função probit com complemento log-log.

A estimativa dos modelos propostos foi realizada no software R-3.6.1, disponível em http://www.r-project.org. A regressão beta foi implementada através do pacote "betareg".

\section{Resultados e Discussão}

Das 254 amostras que foram selecionadas para o cômputo dos dados, 144 são mulheres e 110 são homens. Os casados foram 42,5\% (108) da amostra, enquanto os solteiros, 57,5\% (146). Quanto à escolaridade, 3\% dos entrevistados possuem somente o ensino fundamental; $24 \%$ cursaram o ensino médio por completo. Os que possuem ensino superior são $22 \%$ e os que tem algum tipo de pós-graduação são 51\%. O perfil dos entrevistados é exposto abaixo na Figura 3.

Figura 3 - Perfil dos entrevistados.

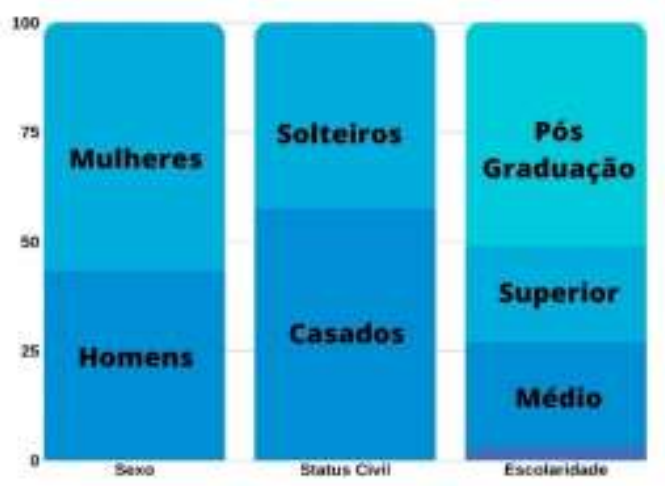

Fonte: Autores (2020).

Quando questionados se voltariam com maior frequência ao município caso as mudanças de melhoria na qualidade ambiental que foram propostas na pesquisa, de fato se concretizassem, $75 \%$ responderam que sim. Os demais $25 \%$, cuja resposta foi "não voltaria com maior frequência", alegaram os mais diversos motivos, para tal resposta. Porém a justificativa de maior frequência foi a questão de tempo, pois já iam com frequência em função das suas folgas laborais, aos finais de semana por exemplo. 
Figura 4 - Percentual de respostas acerca do número de visitas ao município.

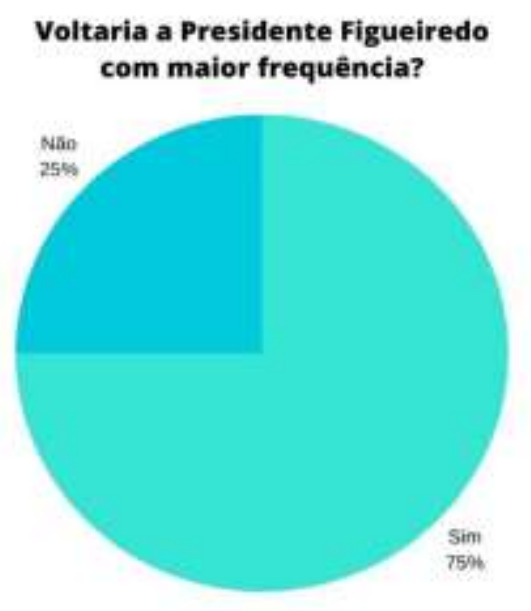

Fonte: Autores (2020).

A idade média da amostra foi de 35 anos. Os indivíduos entrevistados vão, em média, ao município de Presidente Figueiredo entre seis e sete vezes ao ano. A estimativa de dias de permanência no município é mais de um, porém não mais que dois, e a média de gastos por pessoa da família por dia é de R \$130,80.

A DAP diária média é de $\mathrm{R} \$ 12,43$. A renda média familiar da amostra é $\mathrm{R} \$ 6407,00$. Para o cálculo da variável beta "B" a DAP declarada foi dividida pela renda diária do indivíduo. Sendo assim, o "B" médio é de 12,8\%. As demais medidas descritivas estão no quadro abaixo.

Quadro 4 -Medidas descritivas das variáveis.

\begin{tabular}{|l|l|l|l|}
\hline Variáveis & Média & Desvio padrão & Mediana \\
\hline Idade & 35,57 & 11,29 & 32 \\
\hline Idas a PF no último ano & 6,74 & 5,63 & 7 \\
\hline Gastos médios por dia em PF (r\$) & $\mathrm{R} \$ 130,80$ & $\mathrm{R} \$ 101,24$ & $\mathrm{R} \$ 100,00$ \\
\hline Renda mensal (r\$) & $\mathrm{R} \$ 6407,00$ & $\mathrm{R} \$ 5362,00$ & $\mathrm{R} \$ 5000,00$ \\
\hline Dap (r\$) & $\mathrm{R} \$ 12,43$ & $\mathrm{R} \$ 21,49$ & $\mathrm{R} \$ 10,00$ \\
\hline B (dap/renda diária) & $12,8 \%$ & $22,37 \%$ & $4,1 \%$ \\
\hline
\end{tabular}

Fonte: Autores (2020).

Os modelos foram ajustados para estimar a proporção DAP em função da renda diária do indivíduo, com diferentes funções de ligação para verificar a adequação do modelo aos dados da amostra.

A escolha da função de ligação para estimar o modelo foi a que forneceu maior " $\mathrm{R}^{2}$ ", indicando maior probabilidade de que o modelo se ajusta aos dados. Os modelos com funções de ligação "probit" e "logit" foram os que apresentaram maior adequação, frente às funções de ligação "complemento log-log” e "cauchit". O parâmetro de média e precisão $\phi$ é "log” e não matriz "sqrt". O parâmetro "phi” não foi vinculado a quaisquer outros conjuntos.

Para cada resposta foi associada uma "função probabilidade" de acordo com sua ocorrência para aquela amostra. A seguir constam os modelos com as duas funções de ligação. 
Para o modelo logit, o "pseudo $\mathrm{R}^{2}$ " da regressão estimada alcançou $91,58 \%$, indicando ótimo ajuste para o modelo. $\mathrm{O}$ parâmetro de precisão estimado $\emptyset$ foi igual a 4,232 com um erro padrão de 45,06 e significância de <2e-16 ***. A $\log$ verossimilhança foi de 598,4 com 19 graus de liberdade, aceitando a hipótese da adequação do modelo para este estudo.

Para o modelo probit, o "pseudo $\mathrm{R}^{2 "}$ da regressão estimada é de $92,5 \%$, indicando, também, ótimo ajuste para o modelo. O parâmetro de precisão estimado $\emptyset$ é igual a 4,099 com um erro padrão de 43,65 e significância de <2e-16 ***. A estatística da log verossimilhança foi de 579,6 com 17 graus de liberdade.

A respeito da análise dos parâmetros do modelo, com base na literatura econômica sobre valoração contingente, é de se esperar que quanto maior as variáveis educação e renda, maior será a disposição de contribuir para as melhorias ambientais propostas no estudo e por consequência a relação direta dos sinais de um modelo. Entretanto, para o modelo beta, como a resposta é a proporção da DAP em função da renda é de se esperar que, quanto maior a renda e a educação, essa por estar diretamente relacionada àquela, menor será a proporção. Portanto, uma relação de sinal negativo é esperada nesses casos e confirmada. Assim, pode-se afirmar que quanto maior a probabilidade de o indivíduo estar em faixas de renda mais elevadas, menor é seu beta.

Já os parâmetros estimados das variáveis sexo, status civil e a maior frequência de visitas (caso ocorram as mudanças ambientais positivas), não apresentaram significância, indicando que não há correlação entre essas variáveis e a disposição a pagar por melhorias no complexo de cachoeiras de Presidente Figueiredo. Tais parâmetros foram excluídos.

Portanto, após os ajustes, o modelo passa a ter o seguinte aspecto:

Beta $=a+X 1 * P+X 2 * I D+X 3 * C V A+X 4 * D A P+X 5 * C A R+X 6 * R E N+e$

E retornou os seguintes resultados do modelo com ligação Probit:

Quadro 5 -Modelo estimado de regressão beta de melhor ajuste.

\begin{tabular}{|c|c|c|c|}
\hline \multirow[t]{2}{*}{ Variáveis } & \multicolumn{3}{|c|}{ Função de Ligação Probit } \\
\hline & Coeficiente estimado & Valor $\mathbf{Z}$ & $\operatorname{Pr}(>|z|)$ \\
\hline Intercepto & $-2,552$ & $-23,634$ & $* * *$ \\
\hline Probabilidade de pagar a DAP & 4,063 & $-38,049$ & $* * *$ \\
\hline Função Probabilidade Escolaridade & $-0,280$ & $-2,249$ & $*$ \\
\hline Função Probabilidade Idade & 0,151 & 2,351 & * \\
\hline Função Probabilidade CVA & 2,281 & 2,689 & $* *$ \\
\hline $\mathrm{R} \$ 3,00<\mathrm{DAP} \leq \mathrm{R} \$ 5,00$ & 0,425 & 6,757 & $* * *$ \\
\hline $\mathrm{R} \$ 5,00<\mathrm{DAP} \leq \mathrm{R} \$ 10,00$ & 0,681 & 11,700 & $* * *$ \\
\hline $\mathrm{R} \$ 10,00<\mathrm{DAP} \leq \mathrm{R} \$ 15,00$ & 0,871 & 11,499 & **** \\
\hline DAP > R $\$ 15,00$ & 1,156 & 19,008 & $* * *$ \\
\hline Função Probabilidade "carona" & 0,241 & 2,437 & $*$ \\
\hline $\mathrm{R} \$ 2000,00<\mathrm{RENDA} \leq \mathrm{R} \$ 5000,00$ & $-0,224$ & $-5,210$ & $* * *$ \\
\hline $\mathrm{R} \$ 5000,00<\mathrm{RENDA} \leq \mathrm{R} \$ 10000,00$ & $-0,581$ & $-11,926$ & **** \\
\hline $\mathrm{R} \$ 10000,00<\mathrm{RENDA}<\mathrm{R} \$ 15000,00$ & $-0,742$ & $-11,322$ & $* * *$ \\
\hline Precisão do modelo com o link "log" & 4,079 & 43,42 & $* * *$ \\
\hline Número de interações & \multicolumn{3}{|c|}{2 (FISHER) + 22 (BFGS) } \\
\hline Pseudo R2 & \multicolumn{3}{|l|}{0,9257} \\
\hline Máxima Verossimilhança & \multicolumn{3}{|c|}{578,1 com 14 graus de liberdade } \\
\hline
\end{tabular}

Fonte: Autores (2020).

Para obter a melhor estimativa do percentual médio da renda que os indivíduos estão dispostos a pagar para as melhorias do complexo de cachoeiras de Presidente Figueiredo utilizou-se a função resumo da média dos preditores do 
universo das amostras. A função resumo da média dos preditores retornou os seguintes resultados estimados para o modelo de regressão beta supramencionado, seus respectivos valores mínimo e máximo, mediana e média.

Quadro 6 - Resumo dos resultados para beta.

\begin{tabular}{|c|c|c|c|c|c|}
\hline \multirow{2}{*}{$\begin{array}{l}\text { Beta diário para o complexo de cachoeiras } \\
\text { de Presidente Figueiredo }\end{array}$} & \multicolumn{2}{|c|}{ Min. } & Mediana & Média & Máx. \\
\hline & $(\%)$ & 0,29 & 5,37 & 12,91 & 99,87 \\
\hline
\end{tabular}

Fonte: Autores (2020).

As proporções se mostraram bem adequadas, pois se espera uma porção média relativamente baixa da renda para pagamentos do tipo. Os valores máximos são retorno de pessoas que declararam uma DAP maior do que a renda diária, o que pode ser explicado nos casos em que pessoas recebam recursos de terceiros para atividades de lazer, ou mesmo pessoas que são casadas e usufruem da renda do cônjuge, ou ainda pessoas que atribuem valores pessoais muito elevados para a conservação ambiental.

Para estimar o valor do complexo de cachoeiras de Presidente Figueiredo, foi utilizada a renda média nominal diária per capita da amostra. Sendo assim, o valor de beta foi multiplicado pelo valor da renda média diária. O produto dessa operação foi multiplicado pelo número estimado de visitantes para o ano de 2018.

Quadro 7 - Valores estimados da DAP.

\begin{tabular}{|l|l|}
\hline Parâmetro & Valores \\
\hline Renda média diária per capita da amostra (a) & $\mathrm{R} \$ 213,56$ \\
\hline Proporção média da renda disponível para melhorias ambientais no CPPF (b) & $12,91 \%$ \\
\hline Número médio estimado de visitas por dia (c) & 416 \\
\hline DAP diária $(d)=(a) *(b) *(c)$ & $\mathrm{R} \$ 11.469,00$ \\
\hline DAP mensal $(\mathrm{e})=(\mathrm{d}) * 30$ dias & $\mathrm{R} \$ 344.081,04$ \\
\hline DAP anual $(\mathrm{f})=(\mathrm{e}) * 12$ meses & $\mathrm{R} \$ 4.128 .972,45$ \\
\hline
\end{tabular}

Fonte: Autores (2020).

De posse das DAPs diárias, mensal e anual, para calcular o valor associado ao CPPF, assume-se o cálculo da renda perpétua. Na qual a respectiva DAP é posta em função de uma determinada taxa, normalmente a "TR", calculada pelo Banco Central.

A escolha da "TR" baseia-se em recomendações de Solow, (1974), Motta (1997) e Travassos et. al (2018). A adoção de uma taxa muito alta implica uma grande redução no valor presente, distorcendo o valor do bem ambiental atual frente ao futuro, podendo haver uma interpretação equívoca e implicar uma pressão para o uso imediato de tais recursos. Para Morehouse, (1935) e Armas (1981) e a terra é como um bem e tem, portanto, valor derivado de sua renda futura, ou "valor perpétuo".

Nesses casos, o relevante é determinar a relação entre o valor presente, calculado pela DAP, e a renda perpétua. Para tal, o valor presente da perpetuidade considera que o número de parcelas a serem pagas tende ao infinito. Por ser calculados como "parcelas" a DAP escolhida é a mensal. Bem como para determinar o valor a seguir foi adotada a "TR" de agosto de 2017 (0,0098), pois foi a última taxa maior que zero registrada na série histórica do Banco Central do Brasil. 
Quadro 8 - Valor Estimado do complexo de cachoeiras de Presidente Figueiredo.

\begin{tabular}{|l|l|}
\hline Parâmetro & Valores \\
\hline DAP mensal (e) & $\mathrm{R} \$ 344.081,04$ \\
\hline Taxa referencial de agosto de 2017 $(\mathrm{g})$ & 0,0098 \\
\hline Valor associado do complexo de cachoeiras de Presidente Figueiredo $(\mathrm{h})=(\mathrm{e}) /(\mathrm{g})$ & $\mathrm{R} \$ 35.110 .310,20$ \\
\hline
\end{tabular}

Fonte: Autores (2020).

\section{Considerações Finais}

O processo de estimativas de valores para bens que não possuem valor de mercado é suscetível a erros e a vieses amplamente discutidos pela literatura acadêmica, como consta na revisão deste artigo. Apesar de seus constantes esforços para melhoria de suas estimativas, como é o caso da implementação do modelo beta, as estimativas devem ser usadas com parcimônia, tendo o devido cuidado em termos de generalização.

Foi possível concluir que as pessoas estão dispostas, em média, a disponibilizar aproximadamente 13\% de sua renda diária para a conservação e melhoria ambiental do complexo de cachoeiras de Presidente Figueiredo. Tal resultado sinaliza o potencial em termos de gerenciamento do uso público do patrimônio natural em questão.

Beta revelou-se um valor baixo, pois lazer com essas características, de ecoturismo, não seria possível caso a qualidade ambiental não fosse favorável para seu usufruto. Destaca-se aqui, também, a contribuição e importância dos serviços ecossistêmicos prestados pela floresta, para além da própria paisagem que condiciona a realização da atividade vinculada.

Muitos participantes da pesquisa que não dispuseram ou propunham pequenas ofertas de DAP, atribuíram a obrigação da conservação do meio ambiente ao Estado, eximindo-se de obrigação. Esse comportamento reforça a ideia de que o Estado, além da obrigação de conservar os elementos naturais de uso comum, como consta na Constituição Federal de 1988, e como implementador de políticas públicas ambientais, deve cumprir uma outra obrigação igualmente importante: a de educar. Associar ações no campo da educação ambiental com a atividade de visitação atualmente realizada, torna-se elemento oportuno e necessário. Tal perspectiva reforça a necessidade de incremento e implementação de processos de planejamento da atividade, alinhados com as políticas de ordenamento do território e de conservação da biodiversidade. Este último visto como o principal ativo e que sugere uma ação de uso indireto e de caráter público do patrimônio natural.

A disposição a pagar para recreação do complexo de cachoeiras de Presidente Figueiredo é de R $\mathbf{R} \$ 344.081,04$ por mês e R \$4.128.972,45 por ano. Como dito anteriormente, essa estimativa tem caráter balizador, sendo um marco histórico para o município, pois estudo como esse não haviam entrado na esfera de valor monetário.

Por fim, foi possível chegar no valor presente total dos benefícios futuros do complexo de cachoeiras de Presidente Figueiredo: $\mathrm{R} \$ 35.110 .310,20$. Essa quantia é uma aproximação hoje, que representa os benefícios que se tem e que se terá no uso recreativo do CCPF. Vale destacar que para a composição positiva de um cenário futuro, torna-se fator limitante a aplicação de parcela dos recursos oriundos da atividade em ações de planejamento do uso e de ordenamento do território. Considera-se ainda a possibilidade de envolvimento e participação dos usuários, gestores públicos, moradores locais, lideranças e empresários do setor. Caracterizando assim, um processo participativo de planejamento do bem público em questão e que possa ser consolidado em termos de política pública.

Um outro ponto importante destacar é que os valores apurados nesse trabalho podem estar subestimados. Os valores obtidos aumentam à medida que cresce o número de visitantes, pois a disposição a pagar total é calculada pelo número estimado de visitantes do local, ou seja, o crescimento no número de visitantes com fins recreativos aumenta o valor do local. O que faz sentido do ponto de vista teórico, já que, segundo Varian (1987), a demanda (ou procura) é o componente que torna o bem escasso e portanto, de maior valor. 
Outro fator que contribui com o aumento do valor associado a determinada região é a importância que o local tem no consciente social. Locais como Presidente Figueiredo se tornam mais valiosos com o passar dos anos. Percebe-se, portanto, que o valor de $\mathrm{R} \$ 35.110,310,20$ é um número bastante conservador, em se tratando de bens dessa magnitude.

A respeito de uma agenda de trabalhos futuros é possível esperar que publicações de análises de custo-benefício, acerca da implementação de políticas públicas nesse sentido, sejam observadas. Em adição, o problema do carona pode ser abordado com a mesma base de dados, já que é possível observar esse fenômeno nas amostras. Indivíduos que não pagariam pelas melhorias propostas e voltariam com maior frequência no CCPF expõem esse comportamento denominado "carona". Estudos também serão necessários para a definição de um valor monetário, transformado em taxa, para o ingresso em um determinado complexo de cachoeiras, ou ingresso no município. Por fim, estudos de acompanhamento da qualidade ambiental do município devem ser executados para se monitorar e avaliar uma potencial política pública no sentido de taxar o acesso aos ativos naturais do município.

\section{Referências}

Secretaria De Estado De Meio Ambiente do Amazonas (2018). Termo de cooperação Técnica entre os municípios. Autor.

Bateman, I. J., \& Turner, R. K. (1993) Valuation of the environment, methods and techniques: The contingent valuation method. 192-266. Belhaven Press

Ministério do Turismo do Brasil. (2016). Presidente Figueiredo: o paraíso das cachoeiras do Amazonas: http://antigo.turismo.gov.br

Breves da Silva, L. (2014). Valoração econômica dos ativos ambientais provenientes da arborização. Mestrado em Ciências Florestais e Ambientais UFAM, Manaus, Brasil.

Cavalcante, K. V. \& Lopes, R. H. (2017). Implicações socioeconômicas e ambientais do turismo na área urbana de Presidente Figueiredo amazonas. Revista Gestão \& Sustentabilidade Ambiental, 6(3), 313. https://doi.org/10.19177/rgsa.v6e32017313-330

Carriazo, F., Ready, R., \& Shortle, J. (2013). Using stochastic frontier models to mitigate omitted variable bias in hedonic pricing models: A case study for air quality in Bogotá, Colombia. Ecological Economics, (91), 80-88. https://doi.org/10.1016/j.ecolecon.2013.04.005

Clement, R. C \& Higuchi, N. (2006). A floresta Amazônica e o futuro do Brasil. Ciência e Cultura, (58) 3. http://cienciaecultura.bvs.br/scielo.php ?script=sci_arttext\&pid=S0009-67252006000300018

Costanza, R., D’Arge, R., De Groot, R., Farber, S., Grasso, M., Hannon, B., \& Van Den Belt, M. (1997). The value of the world's ecosystem services and natural capital. Nature, 387(6630), 253-260. https://doi.org/10.1038/387253a0

Creswell, J. W. (2010) Projeto de Pesquisa: métodos qualitativo, quantitativo e misto. (3a ed.), Artmed.

Dos Reis, J. R. L. \& Tello, J. C. R. (2010). Gestão ambiental de atrativos turísticos naturais da APA caverna do Maroaga, Presidente Figueiredo/am. Revista Da Anpege, (06), 127-150. https://doi.org/10.5418/ra2010.0606.0009

Faria, R. C \& Nogueira, J. M. (1998). Método de Valoração Contingente: Aspectos Teóricos e Testes Empíricos, 1-24. https://aprender.ead.unb.br/pluginf ile.php/796341/mod_reso urce/content/1/M\%C3\%A9todo\%20de\%20Valora\%C3\%A7\%C3\%A3o\%20Contingente\%20Aspectos\%20Te\%C3\%B 3ricos\%20e\%20Testes\%20Emp\%C3\%ADricos.pdf

Ferrari, S. L. P. \& Cribari-Neto, F. (2004). Beta regression for modelling rates and proportions. Journal of Applied Statistics, 31(7), 799-815. https://doi.org/10.1080/0266476042000214501

Fleming, C. M., \& Cook, A. (2008). The recreational value of Lake McKenzie, Fraser Island: An application of the travel cost method. Tourism Management, 29(6), 1197-1205. https://doi.org/10.1016/j.tourman.2008.02.022

Freeman III, A. M; Herriges, A. J \& Kling, L. C. (2014). The Measurement of Environmental and Resource Values: Theory and Methods. Londres, HWA.

Garrod, G. D., \& Willis, K. G. (1992). Valuing goods' characteristics: An application of the hedonic price method to environmental attributes. Journal of Environmental Management, 34(1), 59-76. https://doi.org/10.1016/S0301-4797(05)80110-0

Gil, A. C. (2010) Como elaborar projetos de pesquisa. (5a ed.), Atlas.

Hanemann, W. M. (1984). Welfare Evaluations in Contingent Valuation Experiments with Discrete Responses. American Journal of Agricultural Economics, 66(3), 332-341. https://doi.org/10.2307/1240800

Hardin, G. (1968). The tragedy of the commons American Association for the Advancement of Science. (3859). 1243-1248.

Higuchi, N., Santos, H. P. dos, Santos, J. dos, Lima, A. J. N., Higuchi, F. G., Higuchi, M. I. G., \& Ayres, I. G. S. S. (2009). Governos locais amazônicos e as questões climáticas globais. (D. Autores, Ed.) (p. 86). 
Research, Society and Development, v. 10, n. 9, e5210917674, 2021

(CC BY 4.0) | ISSN 2525-3409 | DOI: http://dx.doi.org/10.33448/rsd-v10i9.17674

Instituto Brasileiro de Geografia e Estatística. (2010). Censo Demográfico. Autor

Levine, A., \& Macey, J. (2018) Dodd-Frank Is a Pigouvian. Yale Law Journal, (127): https://ssrn.com/abstract=3148270

Mendonça, E. G \& Alecrim, J. D. (2006). Turismo impactos nos aspectos geomorfológicos da área de proteção ambiental Presidente Figueiredo Caverna do Maroaga - AM. Caderno Virtual de Turismo. (2), 19-24. http://www.ivt.coppe.ufrj.br/caderno/index.php/caderno/article/view/117/112

Nogueira, J. M.; Medeiros, M. A. A., \& Arruda, F. S. T. (2000). Valoração econômica do Meio Ambiente: ciência ou empiricismo? Cadernos de Ciência e Tecnologia. (2), 81 - 115: https://seer.sct.embrapa.br/index.php/cct/article/viewFile/8870/4995

Oliveira, K.T.L. (2018). Análise de valoração contingente das praias do bairro Rio Vermelho, Salvador-BA: uma aplicação dos instrumentos econométricos logit e probit. Revista Nexos Econômicos. (9), 134-162. https://periodicos.ufba.br/index.php/revnexeco/article/view/21679

Pessoa, F., \& Ramos, F. (1998). Avaliação de Ativos Ambientais: Aplicação do Método de Avaliação Contingente. Revista Brasileira de Economia. (52). 405426.

Rhodes, R. J; Whitehead, J. C; Smith T. I. J \& Denson, M. R. (1984). A benefit-cost analysis of a red drum stock enhancement program in South Carolina. American Journal of Agricultural Economics. (3), 332-341.

Rivas, A. A. F. (Org.). (2014) Economia e valoração de serviços ambientais utilizando técnicas de preferências declaradas. EDUA.

Rivas, A. A. F; Freitas, C. E \& Mourão, R. M. (2008) Valoração e Instrumentos Econômicos Aplicados Ao Meio Ambiente: Alternativas Para Proteger a Amazônia. Instituto PIATAM.

The Committee for the Prize in Economic Sciences in Memory of Alfred Nobel. (2018). Economic Growth, Technological Change and Climate Change. https://www.nobelprize.org/uploads/2018/10/advanced-economicsciencesprize2018.pdf

Motta, R. S. (1997). Manual para valoração de recursos ambientais. IPEA/MMA/PNUD/CNPQ.

Travassos, S. K. de M. (2012). Valoração econômica de dano ambiental: visão econômica contábil para o caso do Estaleiro Atlântico Sul. (Dissertação de Mestrado) - UFPE, Pernambuco, Brasil.

Varian, R. H. (2006). Microeconomia: Princípios Básicos. Tradução: Maria José Cyhlar e Ricardo Doninelli. Elsevier.

World bank (1995). Environment paper number 13. http://documents1.worldbank.org/curated/en/526671468742557779/pdf/multi-page.pdf

Yin, R. K. (2015) Estudo de caso: planejamento e métodos. (5a ed.), Bookman. 